\title{
Secondary weed infestation of maize cultivated in monoculture after single ploughing and manure fertilization after many-year no-tillage cultivation and direct seeding
}

\author{
Zachwaszczenie wtórne kukurydzy uprawianej w monokulturze \\ po jednorazowej orce i nawożeniu obornikiem \\ po wieloletniej uprawie bezorkowej i siewie bezpośrednim
}

\author{
Piotr Szulc*
}

\begin{abstract}
Summary
The field experiment was carried out in the years 2008-2012 at the Research and Education Unit in Swadzim, at present a part of the Poznań University of Life Sciences. The aim of the study was to analyze influence of ploughing and ploughing with simultaneous ploughing-in a full dose of manure, conducted only once after many years of reduced tillage and direct sowing, on secondary weed infestation of maize cultivated in many-year monoculture. It was demonstrated that interruption of many-year no-tillage cultivation system and direct sowing with one-time deep autumn ploughing with ploughing in a full dose of manure resulted in a significant increase in the number of weeds in the year of the measure. The number and fresh matter of weeds were affected by effectiveness of used herbicides and thermal and humidity conditions during vegetation seasons. Barnyard grass and couch grass were the most troublesome and long-lasting weed secondary infestation species in the maize monoculture.
\end{abstract}

Key words: maize; no-tillage; monoculture; weeds; manure; mineral fertilization

\section{Streszczenie}

Doświadczenie polowe przeprowadzono w latach 2008-2012 na terenie Zakładu Doświadczalno-Dydaktycznego w Swadzimiu, należącego do Uniwersytetu Przyrodniczego w Poznaniu. Celem pracy było poznanie wpływu orki oraz orki z jednoczesnym przyoraniem pełnej dawki obornika, wykonanych jednorazowo po wieloletniej bezorkowej uprawie roli i siewie bezpośrednim na stan zachwaszczenia wtórnego kukurydzy uprawianej w wieloletniej monokulturze. Przerwanie wieloletniej uprawy bezorkowej i siewu bezpośredniego jednorazową głęboką orką jesienną z jednoczesnym przyoraniem obornika spowodowało istotny wzrost liczby chwastów w roku jej wykonania. Liczba oraz świeża masa chwastów kształtowane były skutecznością stosowanych herbicydów oraz przebiegiem warunków termiczno-wilgotnościowych w sezonach wegetacyjnych. Najbardziej uciążliwymi, długotrwale występującymi gatunkami chwastów zachwaszczenia wtórnego w monokulturze kukurydzy były chwastnica jednostronna i perz właściwy.

Słowa kluczowe: kukurydza; uprawa bezorkowa; monokultura; chwasty; obornik; nawożenie mineralne

Uniwersytet Przyrodniczy w Poznaniu

Katedra Agronomii

Dojazd 11, 60-632 Poznań

*corresponding author: pszulc@up.poznan.pl 


\section{Wstęp / Introduction}

Od wielu lat najbardziej rozpowszechnionym systemem przygotowania gleby do siewu roślin uprawnych, niezależnie od warunków glebowych, klimatycznych i ekonomicznych jest uprawa płużna (Radecki i Opic 1991), bardzo kosztowna i czasochłonna (Machul i Księżak 2007). W związku z powyższym coraz więcej uwagi poświęca się poszukiwaniu sposobów zmniejszania nakładów na przygotowanie pola pod zasiew i ochrony upraw przed zachwaszczeniem. Zastąpienie uprawy tradycyjnej uprawą bezorkową i siewem bezpośrednim w ściernisko może być uzasadnione zarówno względami ekonomicznymi, jak i ekologicznymi (Blevins i Frye 1993). W takiej sytuacji należy spodziewać się ciągłych zmian w ilościowym i jakościowym składzie zbiorowisk chwastów, jako efektu wzajemnej ich konkurencji i kompensacji agresywnych taksonów (Domaradzki i Rola 2002). StupnickaRodzynkiewisz i wsp. (2004) twierdzą, że wprowadzenie uproszczeń uprawowych powoduje, że dotychczas stosowane chemiczne metody ograniczania zachwaszczenia mogą stawać się mało efektywne. Zmiany te są tym wyraźniejsze, im dłuższy jest czas stosowania uproszczeń. Dotychczas w Polsce zdaniem Dubasa i wsp. (2012), bezorkowy system uprawy kukurydzy jest stosowany na niewielką skalę. Tym niemniej jest on przedmiotem licznych prac badawczych, których wyniki pozwolą na uzasadnienie celowości jego stosowania (Wrzesińska i wsp. 2003; Owczarzak i wsp. 2009; Księżak i Bojarszczuk 2010; Gołębiowska 2011). Badania dotyczące wieloletniej monokultury kukurydzy uprawianej w systemie bezorkowym są przedmiotem wielu badań prowadzonych w Katedrze Agronomii Uniwersytetu Przyrodniczego w Poznaniu (Menzel i Dubas 2003; Szulc i Dubas 2008; Dubas i wsp. 2012).

Celem pracy było wykazanie wpływu przerwania wieloletniej uprawy bezorkowej jednorazową orką i nawożeniem obornikiem na stan zachwaszczenia wtórnego kukurydzy będącego rezultatem niskiej skuteczności zastosowanego przedsiewnie herbicydu Roundup 360 SL.

\section{Materiały i metody / Materials and methods}

Doświadczenie polowe przeprowadzono w latach 2008-2012 na terenie Zakładu Doświadczalno-Dydak- tycznego w Swadzimiu, należącego do Uniwersytetu Przyrodniczego w Poznaniu. Kukurydza uprawiana była w monokulturze. Badanymi obiektami były:

A - wieloletnia (od roku 1998) uprawa bezorkowa, siew bezpośredni,

B - przerwanie w roku 2007 wieloletniej uprawy bezorkowej jednorazową głęboką orką jesienną $(30 \mathrm{~cm})$,

C - przerwanie w roku 2007 wieloletniej uprawy bezorkowej jednorazową głęboką orką jesienną $(30 \mathrm{~cm})$ i nawożeniem obornikiem.

Badania prowadzono jako doświadczenie jednoczynnikowe, statyczne w 4 powtórzeniach polowych. Obornik bydlęcy zastosowano jednorazowo w ilości $30 \mathrm{t} / \mathrm{ha}$ pod głęboką orkę jesienną w roku 2007. Zawierał on 4,7 g azotu/kg s.m.; 4,9 g fosforu/kg s.m.; 7,8 g potasu/kg s.m. Wykorzystanie składników pokarmowych $\mathrm{z}$ obornika w pierwszym roku po jego zastosowaniu, jak podają Gorlach i Mazur (2002), wynosi: dla azotu 30\%, fosforu $20 \%$ i potasu $30 \%$. Stąd też z dawką $30 \mathrm{t} /$ ha obornika bydlęcego wniesiono do gleby $42,3 \mathrm{~kg} \mathrm{~N} / \mathrm{ha}$, fosforu $29,4 \mathrm{~kg} \mathrm{P}_{2} \mathrm{O}_{5} / \mathrm{ha} \mathrm{i} \mathrm{70,2} \mathrm{kg} \mathrm{K} \mathrm{K}_{2} \mathrm{O} / \mathrm{ha}$. W roku 2008 nawożenie mineralne bilansowano $\mathrm{w}$ oparciu o ilość składników pokarmowych wniesionych w oborniku do wysokości pełnych dawek NPK: $90 \mathrm{~kg} \mathrm{~N} / \mathrm{ha}, 80 \mathrm{~kg} \mathrm{P}_{2} \mathrm{O}_{5} / \mathrm{ha} \mathrm{i} 120 \mathrm{~kg}$ $\mathrm{K}_{2} \mathrm{O} /$ ha. Od roku 2009 do 2012 na obiektach A, B i C stosowano wyłącznie nawożenie mineralne przed siewem kukurydzy. Resztki pożniwne po ich rozdrobnieniu na obiekcie A z wieloletnią uprawą bezorkową pozostawiano na polu bez przykrycia, podobnie jak na obiektach B i C po ich przyoraniu orką jesienią $w$ dalszych latach badań. Ziarno kukurydzy zbierano kombajnem poletkowym firmy Wintersteiger. Chwasty zwalczano wyłącznie chemicznie. We wszystkich latach corocznie stosowano przedsiewnie Roundup $360 \mathrm{SL}$ w dawce 3 1/ha z dodatkiem $5 \mathrm{~kg} / \mathrm{ha}$ siarczanu amonu. Niska jego skuteczność wymuszała konieczność dodatkowego opryskiwania herbicydami powschodowymi, które były również niedostatecznie skuteczne. Ich termin i dawki stosowania przedstawiono w tabeli 1. Pozostałe chwasty na poletkach stanowiły zachwaszczenie wtórne oceniane w okresie kwitnienia kolb na powierzchni $4,34 \mathrm{~m}^{2}$.

Uzyskane wyniki poddano statystycznej analizie zmienności dla doświadczeń jednoczynnikowych ortogonalnych, następnie wykonano syntezę dla doświadczeń wieloletnich. Istotność różnic oszacowano na poziomie $\alpha=0,05$ za pomocą testu t-Studenta. Obliczono też

Tabela 1. Herbicydy powschodowe stosowane w doświadczeniu Table 1. Post-emergence herbicides used in the experiment

\begin{tabular}{c|c|c|c}
\hline $\begin{array}{c}\text { Lata } \\
\text { Years }\end{array}$ & $\begin{array}{c}\text { Herbicyd } \\
\text { Herbicides }\end{array}$ & $\begin{array}{c}\text { Termin zabiegu } \\
\text { Time of application }\end{array}$ & $\begin{array}{c}\text { Dawka } \\
\text { Dose }\end{array}$ \\
\hline 2008 & Guardian Max + Click 500 SC & $\begin{array}{c}\text { faza 1-2 liść } \\
\text { growth stage 1-2nd leaf }\end{array}$ & $2,51 / \mathrm{ha}+1,51 / \mathrm{ha}$ \\
\hline 2009 & Guardian Max + Click 500 SC & $\begin{array}{c}\text { faza 1-2 liść } \\
\text { growth stage 1-2nd leaf }\end{array}$ & $2,51 / \mathrm{ha}+1,51 / \mathrm{ha}$ \\
\hline 2010 & Guardian Complete Mix 664 SE & $\begin{array}{c}\text { faza 2-3 liść } \\
\text { growth stage 2-3rd leaf }\end{array}$ & $3,5 \mathrm{l} / \mathrm{ha}$ \\
\hline 2011 & Guardian Complete Mix 664 SE & $\begin{array}{c}\text { faza 2-3 liść } \\
\text { growth stage 2-3rd leaf } \\
\text { faza 2-3 liść } \\
\text { growth stage 2-3rd leaf }\end{array}$ & $3,5 \mathrm{l} / \mathrm{ha}$ \\
\hline & $\begin{array}{c}\text { Guardian Complete Mix 664 SE } \\
\text { Maister 310 WG + Actirob 842 EC }\end{array}$ & $\begin{array}{c}3,5 \mathrm{l} / \mathrm{ha} \\
0,15 \mathrm{~kg} / \mathrm{ha}+21 / \mathrm{ha}\end{array}$ \\
\hline
\end{tabular}


współczynniki zmienności (CV) analizowanych cech dzieląc odchylenia standardowe przez średnie arytmetyczne mnożąc przez 100 (Elandt 1964).

\section{Wyniki i dyskusja / Results and discussion}

W najbardziej suchym roku 2008 suma opadów atmosferycznych wynosiła $346,3 \mathrm{~mm}$. W pozostałych latach była wyższa i kształtowała się na poziomie od 424,2 mm w roku 2011 do 500,7 mm w roku 2010. Ich rozkład przy mniej zróżnicowanych w latach warunkach termicznych, powodował występowanie okresowych niedoborów wody w glebie. Najbardziej niekorzystny wpływ na przebieg wegetacji i plonowanie kukurydzy miała długa susza występująca w maju i czerwcu w roku 2008 oraz w mniejszym stopniu krótkotrwała susza w okresie nalewania ziarna i dojrzewania w roku 2009 (rys. 1). W pozostałych latach warunki wilgotnościowe i termiczne sprzyjały wzrostowi i rozwojowi kukurydzy.

Zarówno sama orka, jak i orka z jednoczesnym przyoraniem obornika wykonane na obiekcie B i C po wieloletniej uprawie bezorkowej i wyłącznym nawożeniu mineralnym NPK spowodowały zmiany w stanie zachwaszczenia wtórnego kukurydzy wyrażonego liczbą chwastów (tab. 2). Istotnie największą liczbę chwastów stanowiących zachwaszczenie wtórne stwierdzono w pierwszym roku po wykonaniu orki $\mathrm{z}$ jednoczesnym przyoraniem obornika (tab. 2). Na obiekcie tym liczba chwastów, które nie zostały zniszczone zastosowanymi uprzednio herbicydami, w porównaniu do obiektu A z uprawą bezorkową zwięk- szyła się 6-krotnie, a do obiektu B, gdzie po orce stosowano wyłącznie nawożenie mineralne prawie 3-krotnie (tab. 2). W dalszych latach po orce, w tym również po orce z przyoranym obornikiem, liczba chwastów pozostających w zachwaszczeniu wtórnym zależała już tylko od przebiegu warunków pogodowych oraz od skuteczności chwastobójczej stosowanych corocznie herbicydów. Również badania Szulca i Dubasa (2008) potwierdzają, że skuteczność chwastobójcza stosowanych herbicydów w monokulturze kukurydzy jest zależna od panujących warunków meteorologicznych, głównie wilgotnościowych w sezonach wegetacyjnych.

W przeprowadzonych badaniach polowych nie wykazano istotnego wpływu przerwania wieloletniej uprawy bezorkowej jednorazową orką i nawożeniem obornikiem na stan zachwaszczenia wtórnego wyrażonego świeżą masą chwastów (tab. 3). Należy stwierdzić, że wartość tej cechy modyfikowana była wyłącznie przebiegiem warunków termiczno-wilgotnościowych w sezonach wegetacyjnych kukurydzy i skutecznością zastosowanego przed siewem herbicydu Roundup 360 SL oraz zastosowaniem herbicydów powschodowych. Na uwagę zasługuje fakt, iż w roku 2011, który charakteryzował się deficytem wody w sezonie wegetacyjnym (rys. 1), świeża masa chwastów zachwaszczenia wtórnego na obiektach A i B była zdecydowanie większa, w porównaniu do pozostałych lat badań (tab. 3). Uzyskany wynik w badaniach własnych jest zgodny z upowszechnioną wiedzą, że uproszczenia w uprawie roli prowadzą do wzrostu zachwaszczenia, zwłaszcza w pierwszych latach ich stosowania (Blackshaw i wsp.

Tabela 2. Liczba chwastów w zachwaszczeniu wtórnym [szt. $\left./ \mathrm{m}^{2}\right]$ Table 2. Number of weeds in secondary infestation $\left[\mathrm{No} . / \mathrm{m}^{2}\right]$

\begin{tabular}{|c|c|c|c|c|c|c|}
\hline \multirow{2}{*}{$\begin{array}{c}\text { Obiekty } \\
\text { uprawowe } \\
\text { Cultivation } \\
\text { treatments }\end{array}$} & \multicolumn{5}{|c|}{$\begin{array}{l}\text { Lata kalendarzowe/Lata po przerwaniu siewu bezpośredniego w roku } 2007 \\
\text { Calendar years/Years after the cessation of direct sowing in } 2007\end{array}$} & \multirow{2}{*}{$\begin{array}{c}\text { Średnia } \\
\text { Mean }\end{array}$} \\
\hline & $2008 / 1$ & $2009 / 2$ & $2010 / 3$ & $2011 / 4$ & $2012 / 5$ & \\
\hline A & 3,2 & 4,4 & 21,6 & 7,0 & 20,2 & 11,3 \\
\hline B & 7,2 & 2,6 & 22,5 & 5,3 & 29,1 & 13,4 \\
\hline $\mathrm{C}$ & 20,3 & 6,6 & 8,7 & 3,9 & 18,5 & 11,6 \\
\hline $\begin{array}{l}\text { NIR }(0,05) \\
\operatorname{LSD}(0.05)\end{array}$ & 15,81 & r.n. & r.n. & r.n. & r.n. & r.n. \\
\hline
\end{tabular}

r.n. - różnice nieistotne - not significant differences

Tabela 3. Świeża masa chwastów w zachwaszczeniu wtórnym $\left[\mathrm{g} / \mathrm{m}^{2}\right]$

Table 3. Fresh matter of weeds in secondary infestation $\left[\mathrm{g} / \mathrm{m}^{2}\right]$

\begin{tabular}{|c|c|c|c|c|c|c|}
\hline \multirow{2}{*}{$\begin{array}{l}\text { Obiekty } \\
\text { uprawowe } \\
\text { Cultivation } \\
\text { treatments }\end{array}$} & \multicolumn{5}{|c|}{$\begin{array}{l}\text { Lata kalendarzowe/Lata po przerwaniu siewu bezpośredniego w roku } 2007 \\
\text { Calendar years/Years after the cessation of direct sowing in } 2007\end{array}$} & \multirow{2}{*}{$\begin{array}{l}\text { Średnia } \\
\text { Mean }\end{array}$} \\
\hline & $2008 / 1$ & $2009 / 2$ & $2010 / 3$ & $2011 / 4$ & $2012 / 5$ & \\
\hline A & 19,1 & 35,3 & 91,1 & 259,2 & 101,1 & 101,2 \\
\hline $\mathrm{B}$ & 19,6 & 125,8 & 71,4 & 211,4 & 209,6 & 127,6 \\
\hline $\mathrm{C}$ & 39,1 & 101,1 & 35,9 & 98,0 & 226,7 & 100,2 \\
\hline $\begin{array}{l}\text { NIR }(0,05) \\
\operatorname{LSD}(0.05)\end{array}$ & r.n. & r.n. & r.n. & r.n. & r.n. & r.n. \\
\hline
\end{tabular}

r.n. - różnice nieistotne - not significant differences 
2001; Torresem i wsp. 2003). Przyczyną wzrostu zachwaszczenia $w$ tych systemach może być mniejsza skuteczność stosowanych herbicydów, wynikająca z utrudnionego działania związanego z pozostającymi resztkami roślinnymi na powierzchni pola oraz obniżonej ich skuteczności wynikającej z wyższej zawartości substancji organicznej, a tym samym większej adsorpcji herbicydów (Torresem i wsp. 2003). Ponadto pozostające resztki pożniwne na powierzchni pola sprzyjają większej wilgotności gleby i niższej jej temperaturze, co może mieć również wpływ na dynamikę wschodów chwastów (Morris i wsp. 2010).

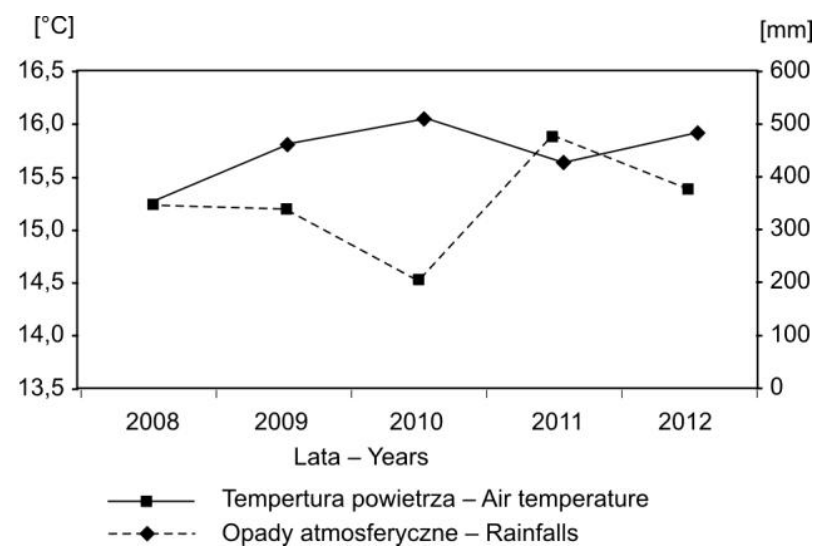

Rys. 1. Średnia temperatura powietrza oraz suma opadów atmosferycznych w sezonach wegetacyjnych

Fig. 1. Mean air temperature and sum of precipitation in vegetation seasons

Wyniki obserwacji zachwaszczenia wtórnego wyrażonego zarówno liczbą, jak i świeżą masą chwastów wskazują na jego dużą zmienność pod wpływem warunków środowiskowych (rys. 2). Istotnie największe zróżnicowanie liczby chwastów stwierdzono na obiekcie B z jednorazową głęboką orką jesienną $(\mathrm{CV}=87,9 \%)$, natomiast najmniejsze zróżnicowanie na obiekcie $\mathrm{C}$ z jednorazową głęboką orką jesienną z przyoraniem pełnej dawki obornika $(\mathrm{CV}=63,6 \%)$. Z kolei największe zróżnicowanie świeżej masy chwastów stwierdzono na obiekcie A z uprawą bezorkową i siewem bezpośrednim $(\mathrm{CV}=93,9 \%)$, natomiast najmniejsze zróżnicowanie tej cechy odnotowano na obiekcie $\mathrm{B} \mathrm{z}$ jednorazową głęboką orką jesienną $(\mathrm{CV}=66,2 \%)$.

W przeprowadzonych badaniach polowych zmieniał się również stan gatunkowy zachwaszczenia wtórnego (tab. 4). Na liście gatunków pojawiających się w tym zbiorowisku, niezależnie od badanych sposobów uprawy roli, odnotowano występowanie 10 taksonów. Największą ich liczbę stwierdzono w roku 2010 (7 gatunków), natomiast najmniejszą w roku 2008 (2 gatunki). Najbardziej uciążliwymi i długotrwale występującymi gatunkami chwastów były Echinochloa crus-galli oraz Elymus repens, które występowały w 4 z 5 lat badań (tab. 4). Z kolei w trzech latach odnotowano występowanie: Chenopodium album, Geranium pusillum i Viola arvensis (tab. 4). Uzyskany

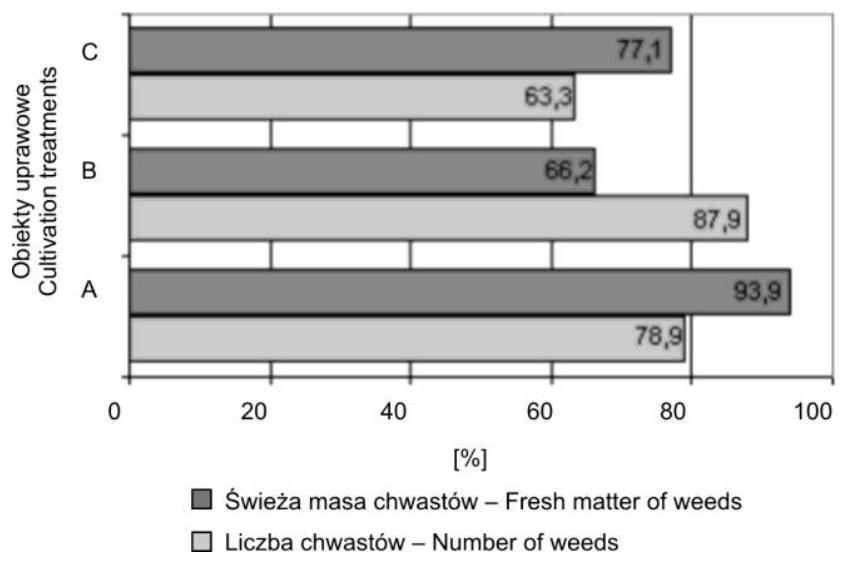

Rys. 2. Współczynniki zmienności analizowanego zachwaszczenia wtórnego (2008-2012)

Fig. 2. Coefficients of variability of analyzed secondary weed infestation (2008-2012)

Tabela 4. Gatunki chwastów w zachwaszczeniu wtórnym, niezależnie od badanych obiektów

Table 4. Weed species in secondary weed infestation, regardless of examined objects

\begin{tabular}{|c|c|c|c|c|c|}
\hline \multirow{2}{*}{$\begin{array}{l}\text { Nazwa polska - Polish name } \\
\text { Nazwa łacińska - Latin name }\end{array}$} & \multicolumn{5}{|c|}{ Lata - Years } \\
\hline & 2008 & 2009 & 2010 & 2011 & 2012 \\
\hline Komosa biała - Chenopodium album $\mathrm{L}$. & + & - & - & + & + \\
\hline Perz właściwy - Elymus repens $\mathrm{L}$. & + & + & + & - & + \\
\hline Rdest powojowaty - Polygonum convolvulus L. & - & + & + & - & - \\
\hline Bodziszek drobny - Geranium pusillum L. & - & + & + & - & + \\
\hline Fiołek polny - Viola arvensis Murray & - & + & + & - & + \\
\hline Bluszczyk kurdybanek - Glechoma hederaceae L. & - & - & + & - & - \\
\hline Szarłat szorstki-Amaranthus retroflexus L. & - & - & - & + & - \\
\hline Iglica pospolita - Erodium cicutarium & - & - & + & - & - \\
\hline Chwastnica jednostronna - Echinochloa crus-galli & - & + & + & + & + \\
\hline Palusznik krwawy - Digitaria sanguininalis & - & - & - & - & + \\
\hline
\end{tabular}

+ chwast występował w danym sezonie wegetacyjnym - the weed was observed in a given vegetation season

- chwast nie występował w danym sezonie wegetacyjnym - the weed absent observed in a given vegetation season 
wynik w badaniach własnych jest potwierdzeniem wcześniejszych doniesień literaturowych (Gołębiowska 2006). Autorka stwierdza, że Ch. album oraz $V$. arvensis to najbardziej uciążliwe chwasty występujące w uprawie kukurydzy w monokulturze. Z kolei Głowacka (2011) wykazała, że gatunkami dominującymi w uprawie kukurydzy są: E. crus-galli, Ch. album, Galinsoga parviflora i Cirsium arvense.

\section{Wnioski / Conclusions}

1. Przerwanie wieloletniej uprawy bezorkowej i siewu bezpośredniego jednorazową głęboką orką jesienną $\mathrm{z}$ jednoczesnym przyoraniem obornika spowodowało istotny wzrost liczby chwastów w pierwszym sezonie wegetacyjnym po jej wykonaniu.

2. Zachwaszczenie wtórne kukurydzy wyrażone liczbą oraz świeżą masą chwastów kształtowane było skutecz- nością stosowanych herbicydów na tle warunków pogodowych w sezonach wegetacyjnych.

3. Najbardziej uciążliwymi, długotrwale występującymi gatunkami chwastów zachwaszczenia wtórnego w monokulturze kukurydzy były E. crus-galli oraz E. repens.

Badania wykonano w ramach Projektu Badawczego nr N N310 026339 finansowanego przez Ministerstwo Szkolnictwa Wyższego.

\section{Podziękowanie / Acknowledgements}

Składam serdeczne podziękowanie Panu Prof. Andrzejowi Dubasowi za umożliwienie przeprowadzenia analizy zachwaszczenia wtórnego w założonym przez Niego doświadczeniu i pomoc przy opracowaniu prezentowanych wyników.

\section{Literatura / References}

Blackshaw R., Larney F., Lindwall C., Watson P., Derksen D. 2001. Tillage intensity and crop rotation affect weed community dynamics in a winter wheat cropping system. Canadian Journal of Plant Science 81: 805-813.

Blevins R., Frye W. 1993. Conservation tillage: An ecological approach to soil management. Advances in Agronomy 51: 33-78.

Domaradzki K., Rola H. 2002. Wpływ długotrwałej uprawy roślin zbożowych na dynamikę zachwaszczenia pola. [The influence of long-term cultivation of cereals on weed infestation dynamic]. Progress in Plant Protection/Postępy w Ochronie Roślin 42 (1): $228-233$

Dubas A., Drzymała S., Mocek A., Owczarzak W., Szulc P. 2012. Wpływ uproszczeń w uprawie roli w wieloletniej monokulturze kukurydzy (Zea mays L.) na właściwości gleby oraz przebieg wegetacji i plonowanie. Wydawnictwo Uniwersytetu Przyrodniczego w Poznaniu: 7-74.

Elandt R. 1964. Statystyka matematyczna w zastosowaniu do doświadczalnictwa rolniczego. PWN, Warszawa, 595 ss.

Głowacka A. 2011. Dominant weeds in maize (Zea mays L.) cultivation and their competitiveness under conditions of various methods of weed control. Acta Agrobotanica 64 (2): 119-126.

Gołębiowska H. 2006. Wpływ wieloletniej uprawy kukurydzy na ziarno na występowanie chwastów. Pamiętnik Puławski 142: $127-136$.

Gołębiowska H. 2011. Diversity of weed infestation depending on maize cropping system. Acta Scientiarum Polonorum, Agricultura 10 (1): 13-23.

Gorlach E., Mazur T. 2002. Chemia rolna. PWN, Warszawa, 345 ss.

Księżak J., Bojarszczuk J. 2010. The economic assessment of maize cultivation depending on pre-sowing tillage system. Acta Scientiarum Polonorum, Agricultura 9 (4): 55-67.

Machul M., Księżak J. 2007. Ocena plonowania kukurydzy w zależności od sposobu przygotowania roli i metody określenia dawki nawożenia azotem w warunkach monokultury i zmianowania. Fragmenta Agronomica 3 (95): 292-299.

Menzel L., Dubas A. 2003. Reakcja kukurydzy uprawianej w monokulturze na uproszczenia w uprawie roli. Pamiętnik Puławski 133: $123-134$

Morris N.L., Miller P.C.H., Orson J.H., Froud-Williams R.J. 2010. The adoption of non-inversion tillage systems in the United Kingdom and the agronomic impact on soil, crops and the environment - A review. Soil and Tillage Research 108: 1-15.

Owczarzak W., Mocek A., Dubas A. 2009. Wpływ uproszczeń uprawowych w monokulturze kukurydzy na kształtowanie struktury poziomów wierzchnich gleby. Inżynieria Rolnicza 5 (114): 219-228.

Radecki A., Opic J. 1991. Metoda siewu bezpośredniego w świetle literatury krajowej i zagranicznej. Roczniki Nauk Rolniczych, Seria A, 109 (2): 119-141.

Stupnicka-Rodzynkiewicz E., Stępniak K., Lepiarczyk A. 2004. Wpływ zmianowania, sposobu uprawy roli i herbicydów na bioróżnorodność zbiorowisk chwastów. Acta Scientiarum Polonorum, Agricultura 3 (2): 235-245.

Szulc P., Dubas A. 2008. Zachwaszczenie kukurydzy uprawianej w wieloletniej monokulturze. [Weed occurrence in maize (Zea mays L.) growing in long-lasting monoculture]. Progress in Plant Protection/Postępy w Ochronie Roślin 48 (1): 317-323.

Wrzesińska E., Dzienia S., Wereszczaka J. 2003. Wpływ systemów uprawy roli na ilość i rozmieszczenie nasion chwastów w glebie. Acta Scientiarum Polonorum, Agricultura 2 (1): 169-175.

Torresem K., Skuterud R., Tandsaether H., Hagemo B. 2003. Long-term experiments width reduced tillage in spring cereals. I. Effect on weed flora, weed seedbank and grain yield. Crop Protection 22: 185-200. 